\title{
Toric Implantable Collamer Lens for the Treatment of Myopic Astigmatism
}

\author{
Majid Moshirfar (DD ${ }^{1-3}$ \\ Nour Bundogii \\ Alyson N Tukan \\ James $\mathrm{H}$ Ellis ${ }^{5}$ \\ Shannon E McCabe (DD ${ }^{1,6}$ \\ Ayesha Patil ${ }^{5}$ \\ Yasmyne C Ronquillo (D) \\ Phillip C Hoopes (D) \\ 'Hoopes Vision Research Center, \\ Hoopes Vision, Draper, UT, 84020, USA; \\ ${ }^{2}$ John A. Moran Eye Center, University of \\ Utah School of Medicine, Salt Lake City, \\ UT, USA; ${ }^{3}$ Utah Lions Eye Bank, Murray, \\ UT, USA; ${ }^{4}$ University of Arizona College \\ of Medicine Phoenix, Phoenix, AZ, USA; \\ ${ }^{5}$ University of Utah School of Medicine, \\ Salt Lake City, UT, USA; ${ }^{6}$ Mission Hills \\ Eye Center, Pleasant Hill, CA, USA
}

Correspondence: Majid Moshirfar

Medical Director Hoopes Vision Research

Center, Hoopes Vision Research Center,

I 1820 S. State Street Suite \#200, Draper,

UT, 84020, USA

Tel + I 80I-568-0200

$\mathrm{Fax}+1$ 80I-563-0200

Email cornea2020@me.com
Purpose: To report visual outcomes following surgical correction of myopic astigmatism with Visian Toric implantable collamer lens (ICL) (STAAR Surgical, Monrovia, CA, USA) at a single tertiary refractive center in the United States.

Patients and Methods: Toric ICL was implanted in 96 eyes (55 patients) with mean preoperative sphere of $-8.98 \pm 3.04$ diopters (D) and cylinder of $-2.67 \pm 1.02 \mathrm{D}$ from December 2018 to February 2021. Primary visual outcomes of efficacy, safety, stability, predictability of refractive correction, and astigmatic analysis were reported at three and twelve months postoperatively. Secondary subjective outcomes included patient-reported dry eye symptoms and glare/halos at postoperative visits. Other secondary outcomes were biometric data and postoperative vault over time.

Results: At three and twelve months, 75 and 46 eyes were evaluated, respectively. At twelve months, the mean manifest refraction spherical equivalent (MRSE) was $-0.23 \pm 0.47 \mathrm{D}$ with $93 \%$ achieving within $\pm 1.00 \mathrm{D}$ of target refraction. The manifest refractive cylinder (MRC) at twelve months was $-0.73 \pm 0.51 \mathrm{D}$, with $86 \%$ within $\pm 1.00 \mathrm{D}$ of target. Uncorrected distance visual acuity (UDVA) was $20 / 20$ or better in $74 \%$ of eyes at twelve months. No patients lost $\geq 2$ lines of corrected distance visual acuity (CDVA) at twelve months. The mean angle of error was $-0.9 \pm 10.2^{\circ}$ at three months and $-1.6 \pm 12.8^{\circ}$ at twelve months. One patient required bilateral lens rotation, four patients underwent secondary enhancement with LASIK/PRK, and seven patients underwent postoperative limbal relaxing incisions.

Conclusion: This initial single-site experience finds Toric ICL implantation for myopic astigmatism to be safe and effective. Patients can achieve markedly improved UDVA in a single surgery with stable vision over time and minimal adverse subjective symptoms.

Keywords: Toric ICL, visian, myopic astigmatism, visual outcomes

\section{Introduction}

Patients with high myopic astigmatism have limited options for surgical correction of refractive error. Corneal refractive procedures like laser-assisted in situ keratomileusis (LASIK) and photorefractive keratectomy (PRK) are constrained by corneal thickness and keratometry for safe ablation and thus, preferred candidates are patients with low to moderate myopic astigmatism. ${ }^{1}$ Over-ablation in patients with high myopic astigmatism can result in postoperative complications such as corneal ectasia and higher order aberrations. ${ }^{2}$ Bioptics strives to address this limitation by distributing the large refractive correction between a corneal laser ablation and an implantable posterior chamber phakic intraocular lens. ${ }^{3,4}$ With the approval of the Visian Toric Implantable Collamer Lens (STAAR Surgical, Monrovia, CA, USA) (Toric ICL) in 2018, patients with high myopic astigmatism now have an alternative option that 
decreases the need for a second surgery. Initial data concerning Toric ICLs shows promise for improved visual acuity with a safe and predictable outcome. ${ }^{5-7}$

To our knowledge, only the Sanders et al Multicenter FDA clinical study ${ }^{5}$ and most recent 2018 Food and Drug Administration (FDA) clinical trial ${ }^{8}$ have investigated outcomes of Toric ICL within the United States. The present study analyzes outcomes after Toric ICL implantation at a single site from December 2018 to February 2021. Visual outcomes include efficacy, safety, stability, and predictability up to twelve months postoperatively. Biometric analysis and subjective measures of dryness and glare/halos are also reported.

\section{Materials and Methods}

This retrospective de-identified study consisted of a chart review of protected medical record data from a single refractive surgery center. Patients who underwent Toric ICL implantation with V4 Visian Toric ICL (STAAR Surgical, Monrovia, CA, USA) by two surgeons from December 2018 to February 2021 were included. Other inclusion criteria were age 18 years and older; $-3.0 \mathrm{D}$ to $-20.0 \mathrm{D}$ myopia; aqueous depth $>3.0 \mathrm{~mm}$; and above minimum age-adjusted endothelial cell density. Any patient with a history of previous ocular diseases other than myopic astigmatism was excluded from the study. Bioptics patients were also excluded.

Preoperative measurements recorded from LENSTAR LS 900 (Haag Streit Switzerland) were (1) axial length; (2) white-to-white value; (3) flat keratometry; (4) flat axis; (5) steep keratometry; (6) steep axis; (7) aqueous depth; and (8) lens thickness. Preoperative ultrasound biomicroscopy (UBM) VUmax (Sonomed Escalon, New Hyde Park, NY) was utilized to measure (1) aqueous depth; (2) sulcus-tosulcus dimension; (3) lenticular rise; and (4) nasal and temporal anterior chamber angles. Preoperative Pentacam Scheimpflug imaging (Oculus Optikgeräte $\mathrm{GmbH}$ ) measured keratometry and pachymetry at the apex.

Patients received one of four available lens implants (12.1 mm, $12.6 \mathrm{~mm}, 13.2 \mathrm{~mm}$, or $13.7 \mathrm{~mm}$ ). The selection of proper Visian Toric ICL size was based upon the Parkhurst nomogram utilizing measurements of sulcus-tosulcus dimension, lenticular rise, and aqueous depth obtained by UBM. Magnitude of sphere and cylinder for the ICL was selected based on STAAR Surgical Online Calculating and Ordering System (OCOS, Monrovia, CA, USA https://evo-ocos.staarag.ch/Live/).
Postoperative visits were conducted at one day, one week, one month, three months, six months, and twelve months after Toric ICL implantation. Outcomes measured by interview and examination at each postoperative visit were (1) intraocular pressure (IOP) measured with Tonopen; (2) uncorrected distance visual acuity (UDVA); (3) corrected distance visual acuity (CDVA); (4) manifest refraction; (5) vault measured by optical coherence tomography (OCT) RTVue-XR Avanti OCT system (Optovue, Inc., Fremont, CA); and (6) subjective data of dry eye symptoms and glare/halos. When available, postoperative Pentacam data were analyzed.

\section{Vector Analysis}

Postoperative refraction data were collected from patient charts at their three month and twelve month postoperative visits. Predicted postoperative refraction was selected as plano with zero cylinder and an axis of $0^{\circ}$ unless monovision was targeted in the patient. For all eyes in which monovision was targeted, the adjusted predicted postoperative sphere was accounted for in vector analysis. The data collected for the vector analysis were entered into the American Society of Cataract and Refractive Surgery astigmatism double-angle plot tool. ${ }^{9}$ Data were compiled and presented in accordance with the method proposed by Abulafia et al. ${ }^{10}$

\section{Toric ICL Surgical Procedure}

At least one week prior to ICL implantation, YAG (YttriumAluminum Garnet) peripheral iridotomies (PI) were performed at the 11 and 1 o'clock positions. In the preoperative area, patients were dilated with phenylephrine hydrochloride $2.5 \%$ and tropicamide $1.0 \%$. Patients' eyes were marked preoperatively by the surgeon at the $0^{\circ}$ and $180^{\circ}$ orientation while the patient was seated in the upright position. Under the operating microscope, the planned axis of orientation of the toric ICL was marked using the preoperative markings for guidance. Two $1 \mathrm{~mm}$ paracenteses were created and dispersive viscoelastic was injected into the anterior chamber. The ICL was inserted through a temporal $3.0 \mathrm{~mm}$ clear corneal incision and placed into the sulcus in the planned orientation. Sterile balanced salt solution was used to irrigate out the remaining viscoelastic (OcuCoat) and the toric lens was again confirmed to be oriented correctly. Miochol-E (acetylcholine chloride, Bausch \& Lomb, Bridgewater, NJ, USA) was injected intracamerally and the PIs were observed to appear patent. Postoperatively, patients received ofloxacin $0.3 \%$ or moxifloxacin $0.5 \%$ four times a day for one week. 
Prednisolone acetate $1 \%$ was also applied topically four times daily for the first week then tapered weekly.

\section{Results}

\section{Patient Demographics and Lens Characteristics}

In this retrospective study, the medical records of 96 eyes (49 right, 47 left) of 55 patients ( 21 male, 34 female) who underwent Toric ICL implantation were evaluated. Fourteen patients underwent unilateral implantation, while 41 patients underwent bilateral implantation. Mean patient age at time of surgery was $33 \pm 8.25$ years (18 to 54 years) (Table 1). The reported number of eyes (n) is reflective of eyes measured for each outcome at each postoperative visit. Preoperative manifest sphere and cylinder ranged from -2.75 to $-20.00 \mathrm{D}$ and -1.50 to $-5.75 \mathrm{D}$, respectively. Preoperative UDVA was worse than $20 / 400$ in 84 eyes (87.5\%). Seventy-nine eyes $(81.3 \%)$ corrected to $20 / 20$ or better preoperatively. Follow up was 96 eyes $(100 \%)$ at one day, 93 eyes $(96.9 \%)$ at one week, 85 eyes $(88.5 \%)$ at one month, 75 eyes $(78.1 \%)$ at three months, 46 eyes $(47.9 \%)$ at six

Table I Preoperative Baseline Characteristics

\begin{tabular}{|c|c|}
\hline Demographics & Mean ISD (Range) | \% (n) \\
\hline Patients (n) & 55 \\
\hline Age (years) & $33 \pm 8.25(18-54)$ \\
\hline Male/Female & $38.2 \%(21) / 61.8 \%(34)$ \\
\hline Unilateral/Bilateral Implantation & $14.6 \%(14) / 85.4 \%(41)$ \\
\hline Parameter & Mean \pm SD $($ range $) \mid \%$ eyes $(n)$ \\
\hline Eyes (n) & 96 \\
\hline OD/OS & $51.0 \%(49) / 49.0 \%(47)$ \\
\hline UDVA* & $1.77 \pm 0.13(1.18$ to 1.80$)$ \\
\hline CDVA* & $0.02 \pm 0.07(-0.13$ to 0.48$)$ \\
\hline MRSE (D) & $-10.31 \pm 3.10(-21.75$ to -4.88$)$ \\
\hline Refracted Sphere (D) & $-8.98 \pm 3.04(-20.0$ to -2.75$)$ \\
\hline Refracted Cylinder (D) & $-2.67 \pm 1.02(-5.75$ to -1.00$)$ \\
\hline Axial length $(\mathrm{mm})$ & $26.74 \pm 1.51$ (24.09 to 31.61$)$ \\
\hline Aqueous Depth (mm) & $3.78 \pm 0.29$ (2.96 to 4.49$)$ \\
\hline White-to-White (mm) & $11.99 \pm 0.41(11.12$ to 13.14$)$ \\
\hline Lenticular Rise (mm) & $0.64 \pm 0.15(0.37$ to 1.01$)$ \\
\hline Sulcus-to-Sulcus (mm) & $11.61 \pm 0.49(10.39$ to 12.73$)$ \\
\hline Corneal thickness $(\mu \mathrm{m})$ & $519.16 \pm 34.05$ (448 to 588$)$ \\
\hline Anterior chamber angle, Nasal & $43.81 \pm 6.45(30.70$ to 62.70$)$ \\
\hline $\begin{array}{l}\text { Anterior chamber angle, } \\
\text { Temporal }\end{array}$ & $44.02 \pm 7.69(31.50$ to 67.80$)$ \\
\hline
\end{tabular}

Note: *Visual acuity reported as LogMAR.

Abbreviations: UDVA, uncorrected distance visual acuity; CDVA, corrected distance visual acuity; MRSE, manifest refraction spherical equivalent; D, diopters. months, and 46 eyes (47.9\%) at twelve months (Table 2). Preoperative and postoperative measurements obtained over time are displayed in Table 2. Data of visual acuity and manifest refraction preoperatively and postoperatively were summarized with standard outcome reporting (Figures 1 and 2). ${ }^{11}$ Patients received one of four available lens implant diameters: four eyes $(4.2 \%)$ were implanted with a $12.1 \mathrm{~mm}, 63$ eyes $(65.6 \%)$ with a $12.6 \mathrm{~mm}, 29$ eyes $(30.2 \%)$ with a $13.2 \mathrm{~mm}$, and no eyes received a $13.7 \mathrm{~mm}$ Toric ICL. Mean Toric ICL sphere, cylinder, and manifest refraction spherical equivalent (MRSE) are presented in Table 3.

\section{UDVA and Efficacy Index}

Visual outcomes at three and twelve months are presented via the standard graphs in Figure $1 \mathrm{~A}-\mathrm{C}$, including cumulative postoperative UDVA, and postoperative UDVA versus preoperative CDVA. At three months postoperatively, 44 eyes $(62.0 \%)$ achieved UDVA of $20 / 20$ or better. At twelve months, 35 eyes (74.0\%) achieved UDVA of 20/20 or better (Figure 1A). The efficacy index was 0.92 at three months and 0.98 at twelve months. Postoperative visual acuity is compared to preoperative visual acuity in Table 2 .

\section{CDVA and Safety Index}

The UDVA was the same or better than the preoperative CDVA in $66 \%$ of eyes at three months and $74 \%$ of eyes at twelve months postoperatively (Figure 1B). At three months, $42 \%$ of eyes gained one line of CDVA and $4 \%$ gained $\geq 2$ lines, while at twelve months $19 \%$ of eyes gained one line and $5 \%$ gained $\geq 2$ lines (Figure 1C). At three months, $3 \%$ of eyes ( 2 eyes) lost one line of CDVA and at twelve months $5 \%$ of eyes (same 2 eyes) lost one line, both of which went from 20/15 preoperatively to 20/ 20 postoperatively. Of eyes seen at twelve months $(n=43)$, 0 eyes lost CDVA of $\geq 2$ lines compared to preoperative CDVA. The safety index was 1.14 at three months and 1.10 at twelve months.

\section{Stability and Predictability}

The postoperative MRSE and manifest refractive cylinder (MRC) over time are reflected in Table 2. The attempted vs achieved MRSE at three months has a slope of 0.94, indicating slight undercorrection, while the slope at twelve months is 1.02, indicating slight overcorrection (Figure 1D). There was no change in the MRSE between one and twelve months (Figure 1F). Within $0.50 \mathrm{D}$ of target was achieved in $77 \%$ of eyes at three months and 
Table 2 Pre and Postoperative Visual Outcomes at Postoperative Time Points

\begin{tabular}{|c|c|c|c|c|c|c|c|}
\hline Parameters & Pre-Operative & POD I & I wk & I mo & $3 \mathrm{mo}$ & $6 \mathrm{mo}$ & $12 \mathrm{mo}$ \\
\hline $\begin{array}{l}\text { Number of } \\
\text { eyes (patients) }\end{array}$ & $96(55)$ & $96(55)$ & $93(53)$ & 85 (49) & $75(44)$ & $46(26)$ & $46(27)$ \\
\hline UDVA* & $\begin{array}{l}1.77 \pm 0.13 \\
(1.18 \text { to } 1.80)\end{array}$ & $\begin{array}{l}0.11 \pm 0.22 \\
(-0.15 \text { to } 1.30)\end{array}$ & $\begin{array}{l}0.22 \pm 0.28 \\
(0.10 \text { to } 1.18)\end{array}$ & $\begin{array}{l}0.31 \pm 0.38 \\
(0.00 \text { to } 1.18)\end{array}$ & $\begin{array}{l}0.23 \pm 0.36 \\
(0.10 \text { to } 1.18)\end{array}$ & $\begin{array}{l}0.10 \pm 0.00 \\
(0.10 \text { to } 0.10)\end{array}$ & $\begin{array}{l}0.10 \pm 0.00 \\
(0.10 \text { to } 0.10)\end{array}$ \\
\hline CDVA* & $\begin{array}{l}0.02 \pm 0.07 \\
(-0.13 \text { to } 0.48)\end{array}$ & $\begin{array}{l}0.14 \pm 0.21 \\
(-0.13 \text { to } 0.40)\end{array}$ & $\begin{array}{l}0.01 \pm 0.05 \\
(-0.13 \text { to } 0.10)\end{array}$ & $\begin{array}{l}0.10 \pm 0.00 \\
(0.10 \text { to } 0.10)\end{array}$ & $\begin{array}{l}0.10 \pm 0.00 \\
(0.10 \text { to } 0.10)\end{array}$ & $\begin{array}{l}0.10 \pm 0.00 \\
(0.10 \text { to } 0.10)\end{array}$ & $\begin{array}{l}0.10 \pm 0.00 \\
(0.10 \text { to } 0.10)\end{array}$ \\
\hline MRSE (D) & $\begin{array}{l}-10.31 \pm 3.10 \\
(-21.75 \text { to }-4.88)\end{array}$ & $\begin{array}{l}-2.75 \pm 2.68 \\
(-6.50 \text { to }+0.38)\end{array}$ & $\begin{array}{l}-0.12 \pm 0.47 \\
(-2.00 \text { to }+0.63)\end{array}$ & $\begin{array}{l}-0.24 \pm 1.09 \\
(-6.75 \text { to }+2.50)\end{array}$ & $\begin{array}{l}-0.33 \pm 1.12 \\
(-6.75 \text { to }+2.00)\end{array}$ & $\begin{array}{l}-0.13 \pm 0.54 \\
(-1.50 \text { to }+1.75)\end{array}$ & $\begin{array}{l}-0.23 \pm 0.47 \\
(-1.25 \text { to } 1.50)\end{array}$ \\
\hline $\begin{array}{l}\text { Refractive } \\
\text { Sphere (D) }\end{array}$ & $\begin{array}{l}-8.98 \pm 3.04 \\
(-20.00 \text { to }-2.75)\end{array}$ & $\begin{array}{l}-2.36 \pm 2.83 \\
(-6.50 \text { to }+0.75)\end{array}$ & $\begin{array}{l}+0.24 \pm 0.40 \\
(-0.75 \text { to }+1.00)\end{array}$ & $\begin{array}{l}+0.10 \pm 1.06 \\
(-6.25 \text { to }+3.00)\end{array}$ & $\begin{array}{l}+0.01 \pm 1.14 \\
(-6.25 \text { to }+2.50)\end{array}$ & $\begin{array}{l}+0.28 \pm 0.64 \\
(-0.75 \text { to }+3.00)\end{array}$ & $\begin{array}{l}+0.14 \pm 0.60 \\
(-1.00 \text { to }+3.00)\end{array}$ \\
\hline $\begin{array}{l}\text { Refractive } \\
\text { Cylinder (D) }\end{array}$ & $\begin{array}{l}-2.67 \pm 1.02 \\
(-5.75 \text { to }-1.50)\end{array}$ & $\begin{array}{l}-0.79 \pm 0.68 \\
(-1.75 \text { to } 0.00)\end{array}$ & $\begin{array}{l}+0.24 \pm 0.40 \\
(-1.75 \text { to } 0.00)\end{array}$ & $\begin{array}{l}-0.68 \pm 0.43 \\
(-2.25 \text { to } 0.00)\end{array}$ & $\begin{array}{l}-0.68 \pm 0.38 \\
(-1.50 \text { to } 0.00)\end{array}$ & $\begin{array}{l}-0.82 \pm 0.52 \\
(-2.50 \text { to } 0.00)\end{array}$ & $\begin{array}{l}-0.73 \pm 0.51 \\
(-3.00 \text { to }-0.25)\end{array}$ \\
\hline
\end{tabular}

Notes: *Visual acuity reported as LogMAR. Values reported as mean \pm SD (range).

Abbreviations: UDVA, uncorrected distance visual acuity; CDVA, corrected distance visual acuity; MRSE, manifest refraction spherical equivalent.

$80 \%$ of eyes at twelve months (Figure 1E). Ninety-five percent of eyes at three months and $94 \%$ of eyes at twelve months achieved within $\pm 1.00 \mathrm{D}$ of target MRSE (Figure 1E). MRC at twelve months was $-0.73 \pm 0.51$ D (Table 2), with $49 \%$ achieving within $\pm 0.50 \mathrm{D}$ and $86 \%$ within $\pm 1.00 \mathrm{D}$ of target (Figure 2A).

\section{Vector Analysis}

Figures 3 and 4 summarize preoperative and postoperative refractive astigmatism at three and twelve months, respectively. The preoperative datapoints reflect only eyes measured at the corresponding three or twelve month visit. The preoperative refractive astigmatism centroid was $1.28 \pm 1.78 \mathrm{D}$ at $90^{\circ}$. The centroid of postoperative refractive astigmatism was $0.39 \pm 0.66 \mathrm{D}$ at $103^{\circ}$ at three months (Figure 3) and $0.44 \pm 0.80 \mathrm{D}$ at $94^{\circ}$ at twelve months (Figure 4). The postoperative ellipse decreased in the postoperative corneal plane when compared to the ellipse from the preoperative refractive astigmatism. The ellipse decreased from $\sim 3.00 \mathrm{D}$ to $\sim 1.00$ $\mathrm{D}$ in the postoperative corneal plane compared to preoperative measures.

There was a prediction error $\leq 1.00 \mathrm{D}$ in $89 \%$ of eyes and $\leq 0.50 \mathrm{D}$ in $44 \%$ of eyes evaluated at three months, and $\leq 1.00 \mathrm{D}$ in $86 \%$ of eyes and $\leq 0.50 \mathrm{D}$ in $49 \%$ of eyes evaluated at twelve months (Figure 2A). The mean target induced astigmatism (TIA) at three months was $2.11 \pm$ $0.86 \mathrm{D}$ and surgically induced astigmatism (SIA) was $1.87 \pm 1.03 \mathrm{D}$ with a slope of 1.05 . At twelve months, the TIA was $2.16 \pm 0.86 \mathrm{D}$ and SIA was $1.75 \pm 0.85$ $\mathrm{D}$ with a slope of 0.93 (Figure 2B). Mean angle of error was $-0.9 \pm 11.2^{\circ}$ at three months and $-1.6 \pm 12.8^{\circ}$ at twelve months (Figure 2C).

\section{Changes in Vault Over Time}

Biometric data collected on preoperative testing is summarized in Table 1. The average postoperative vault was stable over time $(p=0.05)$ (Figure 5). Mean vault was 580 $\pm 222 \mu \mathrm{m}(100$ to $1100 \mu \mathrm{m})$ at one day, $588 \pm 270 \mu \mathrm{m}(50$ to $1580 \mu \mathrm{m})$ at one week, $526 \pm 189 \mu \mathrm{m}$ (75 to $1000 \mu \mathrm{m})$ at one month, $558 \pm 181 \mu \mathrm{m}$ (175 to $966 \mu \mathrm{m})$ at three months, $482 \pm 220 \mu \mathrm{m}$ (100 to $988 \mu \mathrm{m})$ at six months, and $472 \pm 205 \mu \mathrm{m}(112$ to $850 \mu \mathrm{m})$ at twelve months (Figure 5).

\section{Intraocular Pressure Over Time}

The mean preoperative IOP was $14.61 \pm 2.99 \mathrm{mmHg}$ ( 9 to $27 \mathrm{mmHg}$ ), compared to a mean IOP of $13.15 \pm 4.12$ $\mathrm{mmHg}$ ( 6 to $31 \mathrm{mmHg}$ ) on postoperative day one. The IOP was highest at one month, with a mean of $17.09 \pm$ $4.83 \mathrm{mmHg}$ ( 9 to $32 \mathrm{mmHg}$ ). The mean IOP was within normal limits at one year postoperatively, mean $14.73 \pm$ $3.31 \mathrm{mmHg}$ (7 to $21 \mathrm{mmHg}$ ) (Figure 6).

\section{Rotational Analysis}

Eighty-seven percent of patients had rotation $<5^{\circ}$ and required no additional intervention. Of the thirteen eyes $(13 \%)$ that required secondary intervention for residual 


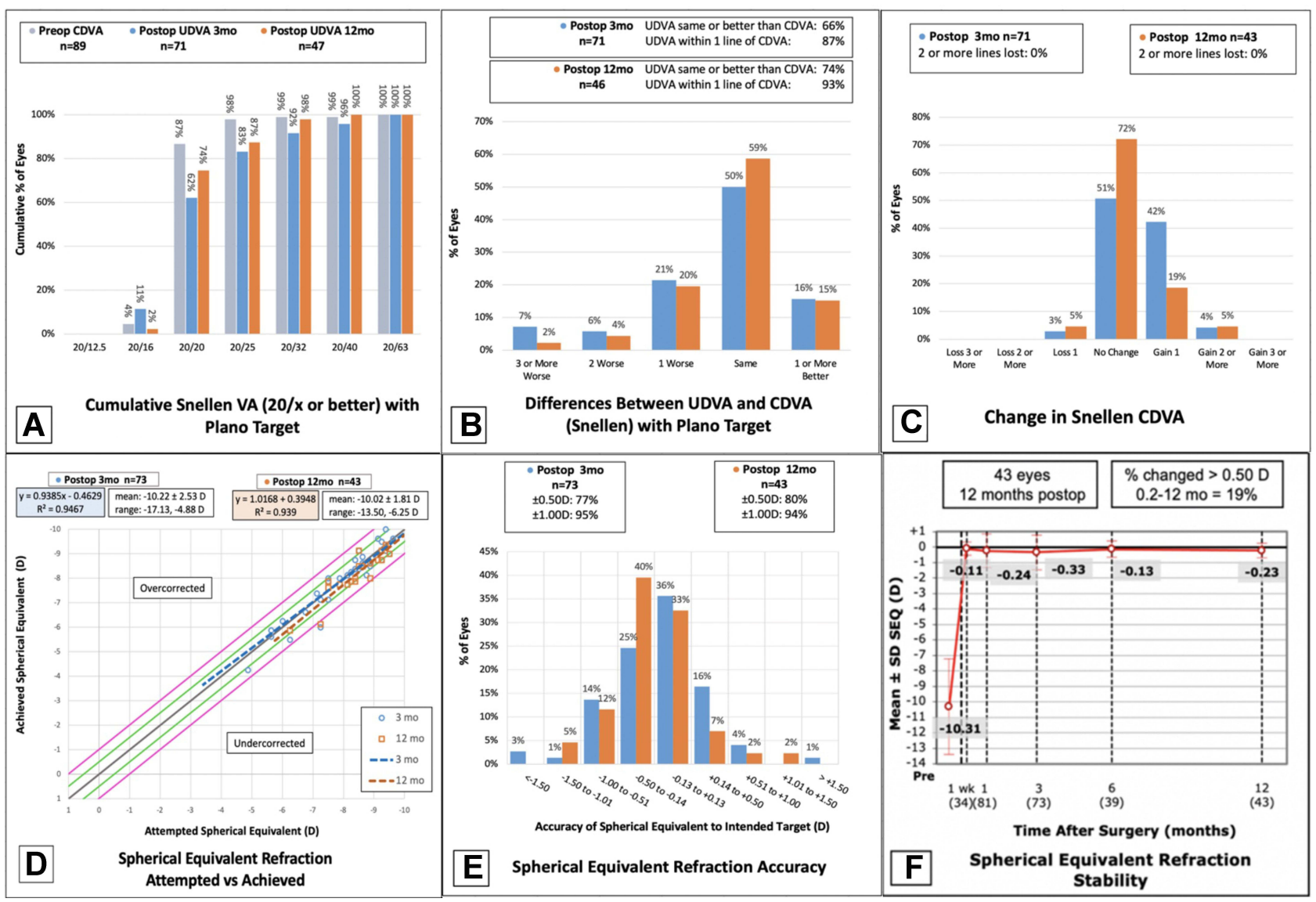

Figure I Standard reporting of visual and refractive outcomes for eyes at three and twelve months following Toric ICL implantation. (A) Cumulative preoperative CDVA and postoperative UDVA; (B) difference between postoperative UDVA and CDVA; (C) change in CDVA; (D) attempted versus achieved MRSE; (E) accuracy of MRSE; (F) stability of MRSE over time.

Abbreviations: UDVA, uncorrected distance visual acuity; CDVA, corrected distance visual acuity; MRSE, manifest refraction spherical equivalent; D, diopter.

astigmatism, eleven eyes underwent additional surgical enhancement for rotation between $5^{\circ}$ and $15^{\circ}$ after proven stability over time. Three eyes underwent PRK, one eye underwent LASIK, and seven eyes underwent postoperative limbal relaxing incisions (LRI). One patient underwent bilateral lens ICL repositioning, with axis rotation of $27^{\circ}$ clockwise, right eye and $16^{\circ}$ counterclockwise, left eye.

\section{Subjective Measures}

Patient-reported dry eye symptoms were present in $13 \%$ of eyes on postop day one, peaked at three months $(29 \%$ of eyes) and demonstrated improvement with only one patient reporting bilateral dry eye symptoms at twelve months (Figure 7). The rate of patient-reported glare/ halos decreased over postoperative time (Figure 8). Thirtynine percent of eyes had glare/halos at one month, which improved to $15 \%$ of eyes at twelve months.

\section{Complications}

No intraoperative complications were recorded. No lenses were explanted postoperatively and no patients were noted to have lens opacification on postoperative exams through twelve months follow-up. Three eyes in two patients required immediate postoperative enlargement of PI using YAG laser to avoid impending angle closure glaucoma. Pressure was adequately relieved with no subsequent adverse events. No other postoperative adverse events were noted.

\section{Discussion}

This single-center study evaluates the visual outcomes after Toric ICL implantation. As reported in previous studies, ${ }^{1,5,6,8,12,13}$ our results support that the Toric ICL is a safe, effective, and stable option for patients with myopic astigmatism. The outcomes in the present study exceeded the Food and Drug Administration (FDA) clinical 


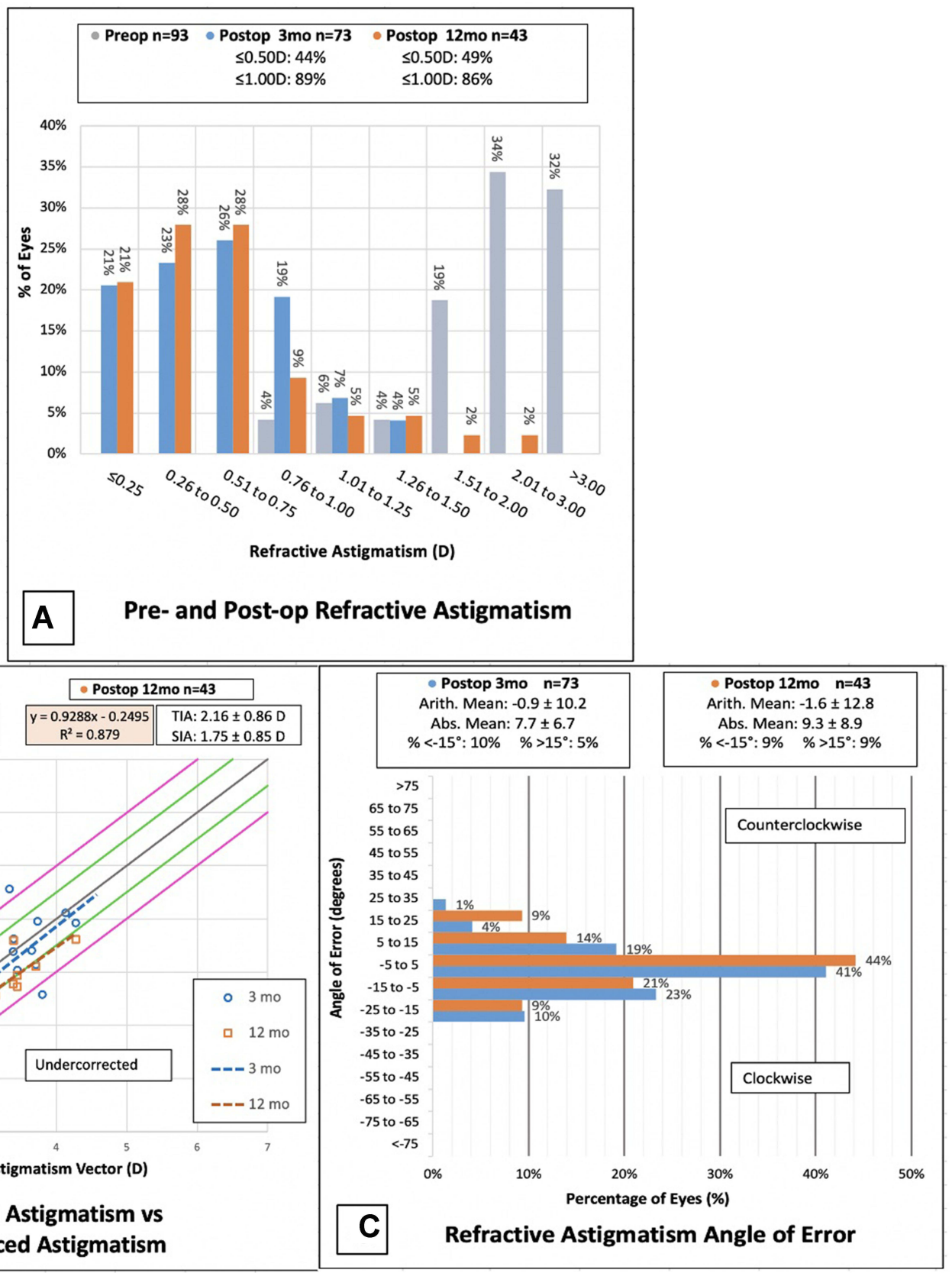

Figure 2 Outcomes of refractive astigmatism for eyes at three and twelve months following Toric ICL implantation. (A) Change in magnitude of refractive astigmatism preversus postoperatively. (B) Magnitude of TIA versus SIA. (C) Postoperative angle of error.

Abbreviations: TIA, target induced astigmatism; SIA, surgically induced astigmatism; D, diopters.

endpoints for safety, efficacy, and predictability with comparable MRSE to other studies on Toric ICL (Table 4). Regarding MRC, Kamiya et al had the most predictable MRC, with $92 \%$ of eyes achieving within $\pm 0.50 \mathrm{D}$ of target and $94 \%$ of eyes achieving within $\pm 1.00 \mathrm{D}$ at 36 months postoperatively. ${ }^{6}$ The FDA clinical trial of Toric ICL also had a high percentage of eyes within $\pm 1.00 \mathrm{D}$ of MRC target at 12 months $(92.3 \%) .{ }^{8}$ Our MRC was less predictable than these studies at 12 months, with $43 \%$ of eyes within $\pm 0.50 \mathrm{D}$ and $80 \%$ within $\pm 1.00 \mathrm{D}$, possibly due to high patient preoperative MRC with 10 eyes $(10.4 \%)>4.00 \mathrm{D}$ (Table 4).

In our study, two eyes (3\% at three months) and the same two (5\% at twelve months) were reported to have lost one line of CDVA. These eyes read 20/15 at preoperative visit and 20/20 at the postoperative visit. This may be due to examiner technique as patients were not always asked to read beyond the 20/20 line. 
Table 3 Implant Characteristics

\begin{tabular}{|l|l|}
\hline Parameter & Median (Range) | \% Eyes (n) \\
\hline Size (mm) & \\
I2.I & $4.2 \%(4)$ \\
12.6 & $65.6 \%(63)$ \\
13.2 & $30.2 \%(29)$ \\
I3.7 & $0 \%(0)$ \\
\hline MRSE (D) & $-10.50(-5.75$ to -15.00$)$ \\
\hline Refractive Sphere (D) & $-12.00(-6.50$ to -16.00$)$ \\
\hline Refractive Cylinder (D) & $2.50(+1.00$ to +4.00$)$ \\
\hline
\end{tabular}

Abbreviations: MRSE, manifest refraction spherical equivalent; D, diopters.

As expected, the postoperative centroid and ellipse decreased after Toric ICL implantation. These findings indicate improvement in astigmatism following surgery. At three months, the slope of the TIA versus SIA (1.05) trends towards overcorrection, while at twelve months the slope demonstrates undercorrection (0.93). This is likely due to slight lens rotation over time compounded by patient attrition. Because $74 \%$ and $87 \%$ of eyes had UDVA $\geq 20 / 20$ and $20 / 25$, respectively, at twelve months, we infer that the Toric ICL has utility for improving vision and correcting high myopic astigmatism even when accuracy of postoperative refraction and astigmatism correction is less than intended.

Rotational stability is an important component of visual outcomes over time in Toric ICL implantation. Studies that assessed axis misalignment on postoperative exams are summarized in Table 5. ${ }^{5,8,14}$ Astigmatic analysis and rotational stability in the current study were based on observation, as patients were not always dilated for precise objective measurement of rotation at each postoperative visit. Eleven eyes had visually significant residual astigmatism, which was attributed to undercorrection and postoperative rotation between $5^{\circ}$ and $15^{\circ}$. These eyes were enhanced with PRK, LASIK or LRIs. Intraoperative $3.0 \mathrm{~mm}$ temporal clear corneal incisions likely contributed to the observed residual astigmatism, which is a reminder for surgeons to be mindful of the plane of incisions relative to the astigmatic axis. Only one patient required lens rotation after original surgery $\left(27^{\circ}\right.$ clockwise, right eye and $16^{\circ}$ counterclockwise, left eye). Although clockwise rotation of the right ICL and counterclockwise rotation of the left ICL were observed, literature is lacking in documentation of the degree and axis of rotation that occurs

\section{Preoperative Refractive Astigmatism}
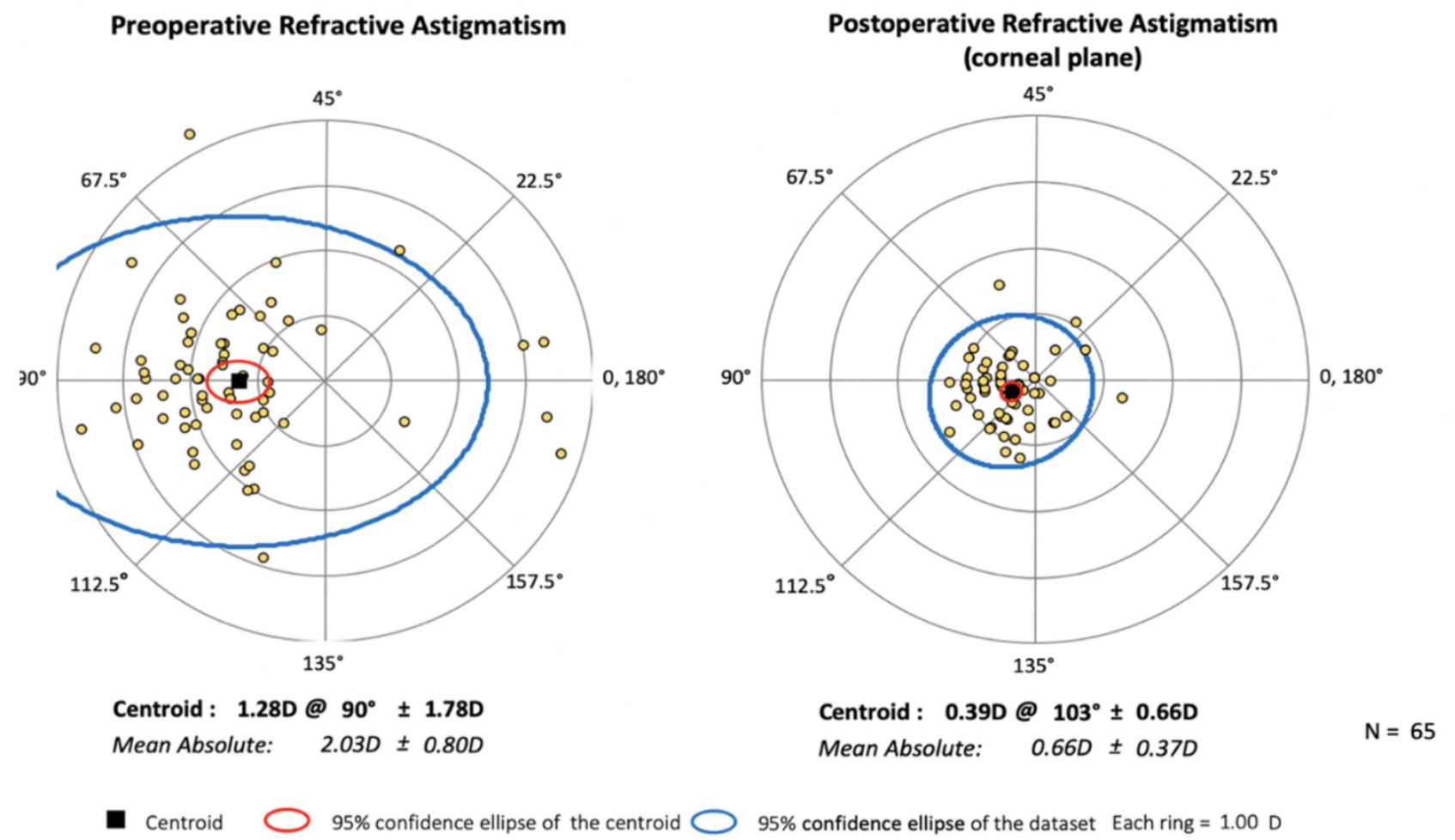

Figure 3 Preoperative and three month postoperative refractive astigmatism ( $n=65$, D diopters). 
Preoperative Refractive Astigmatism

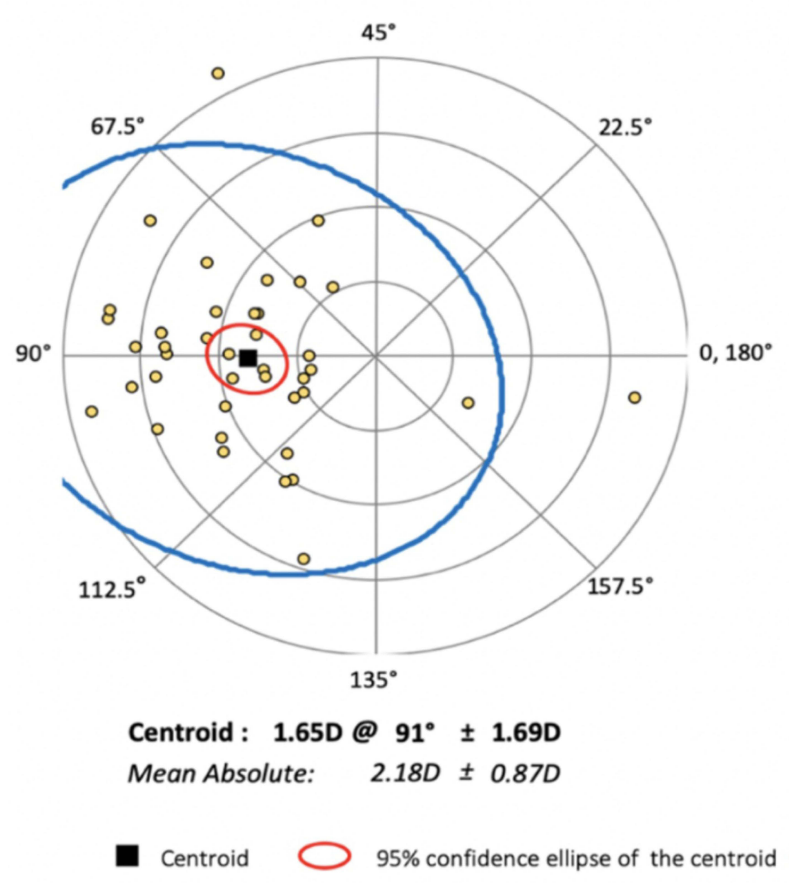

Postoperative Refractive Astigmatism (corneal plane)

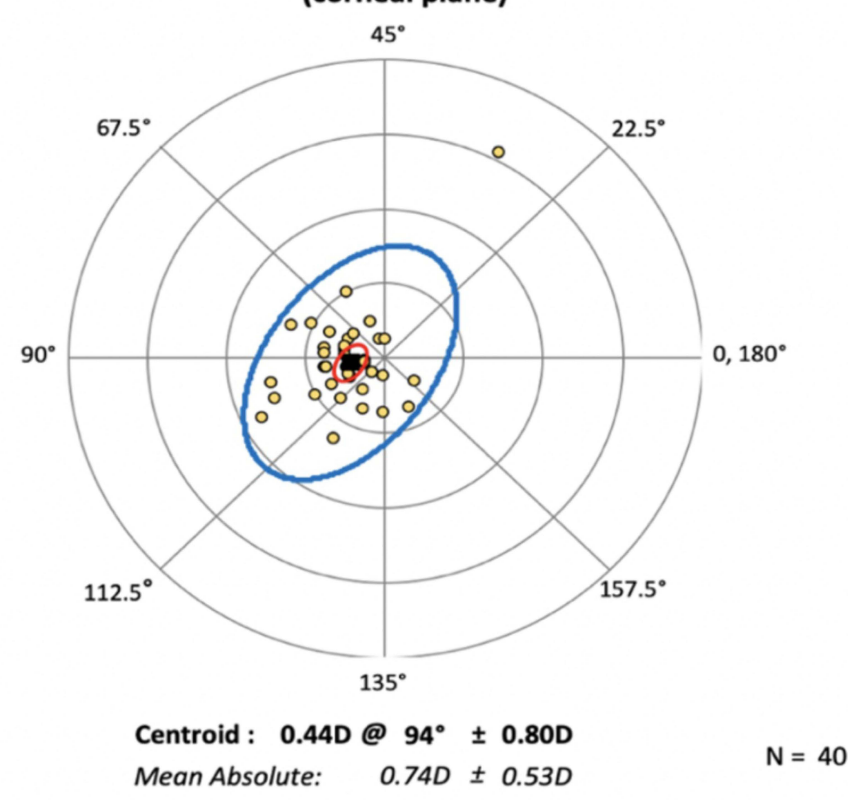

$95 \%$ confidence ellipse of the dataset Each ring $=1.00 \mathrm{D}$

Figure 4 Preoperative and twelve month postoperative refractive astigmatism ( $n=40, D$ diopters).

postoperatively. Further investigation is needed to better understand rotational trends. As more data is collected in this regard, preoperative axis planning may be able to correct for postoperative lens rotation.

Though lens opacity was not noted in any eyes of our study, cataract formation, especially anterior subcapsular morphology, is a known complication after ICL implantation with mean onset of $3.4 \pm 1.9$ years postoperatively. ${ }^{15}$ Rates of cataract formation have been reported from $5.2 \%{ }^{16}$ up to $29 \%{ }^{15}$ for visually insignificant lens opacification. The newer V4c and V5 Toric ICL models have been reported to have decreased associated postoperative lens opacification. ${ }^{17}$ It is thought that a small vault may contribute to cataract formation. ${ }^{16}$ In this study, vault over time was stable as of the twelve month follow-up (postoperative mean range 472.22 to $587.86 \mu \mathrm{m}$ ), though it would be helpful to continue evaluating vault data longterm. Vault measurements were reported as obtained from physician slit lamp examinations. Alfonso et al compared subjective vault measurements and found they were highly correlated with objective measurements obtained on OCT, supporting the validity of our vault measurements. ${ }^{18}$

Transient increase in IOP after Visian ICL implantation is a common finding, ${ }^{16}$ with steroid response possibly contributing to the postoperative elevation. Three eyes of two patients who experienced threatened acute angle closure glaucoma were observed in the present study. Newer Toric ICL models with a central port (V4c and V5) to increase aqueous flow have been shown to decrease postoperative angle closure glaucoma. ${ }^{19}$ Significant anterior chamber angle narrowing has been noted in other studies, ${ }^{20,21}$ though patients in the present study did not undergo postoperative UBM to correlate anterior chamber angle changes with IOP. Other possible complications include pigment dispersion, ${ }^{15}$ uveitis with cystoid macular edema ${ }^{15}$ toxic anterior segment syndrome, ${ }^{13}$ and endophthalmitis, ${ }^{13,22}$ none of which were seen in our study.

Dry eye symptoms are most common in corneal refractive surgeries like LASIK and PRK, with one study noting that $59.4 \%$ of patients experienced dry eyes at one month, ${ }^{23}$ while another study observed a decrease in tear production by $14.57 \%$ post-PRK and $23.40 \%$ post-LASIK at six months postoperatively. ${ }^{24}$ Although ICL implantation induces a smaller insult to corneal anatomy than refractive surgery, evidence from cataract surgery suggests that even a small corneal incision can transect the corneal nerve plexus and cause postsurgical inflammation, 


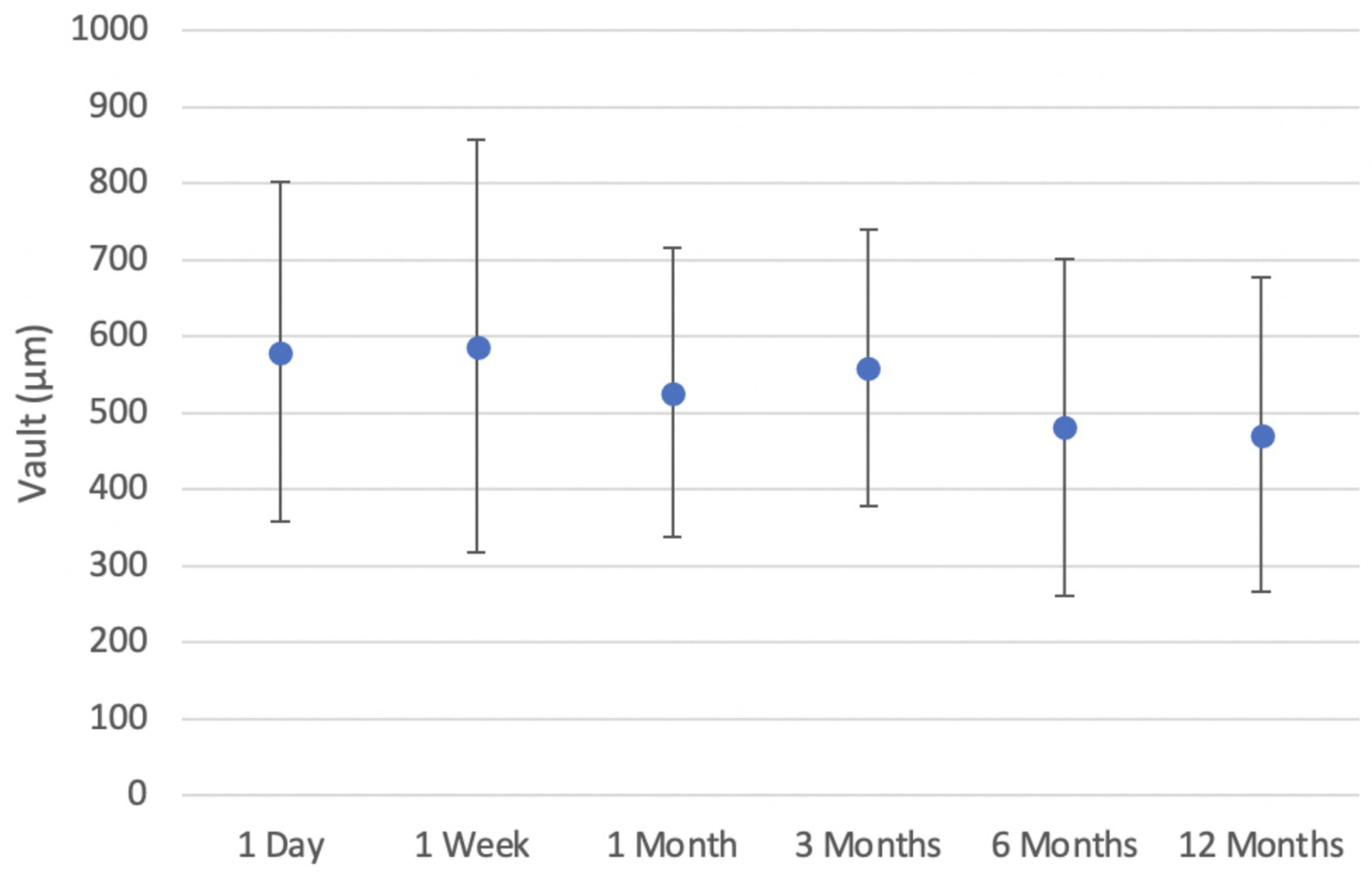

Figure 5 Mean subjective vault over postoperative time.

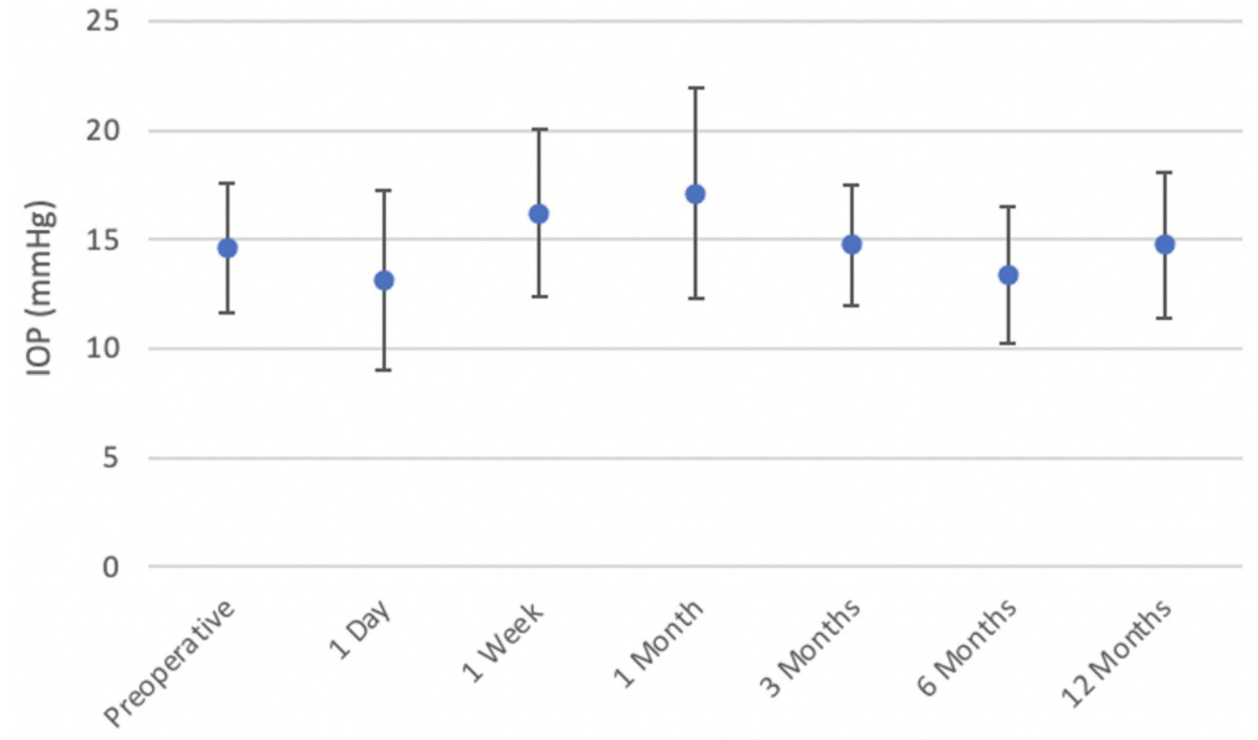

Figure 6 Mean measured IOP preoperatively and over postoperative time.

resulting in aqueous tear deficiency, ${ }^{25}$ with rates of postcataract dryness ranging from approximately $9 \%$ to $40 \%{ }^{26}$ Postoperative dryness was observed in the present study, with peak reported dryness of $29 \%$ at three months, which subsequently decreased over time. Dry eye symptoms prior to surgery were not recorded; thus, residual dryness 


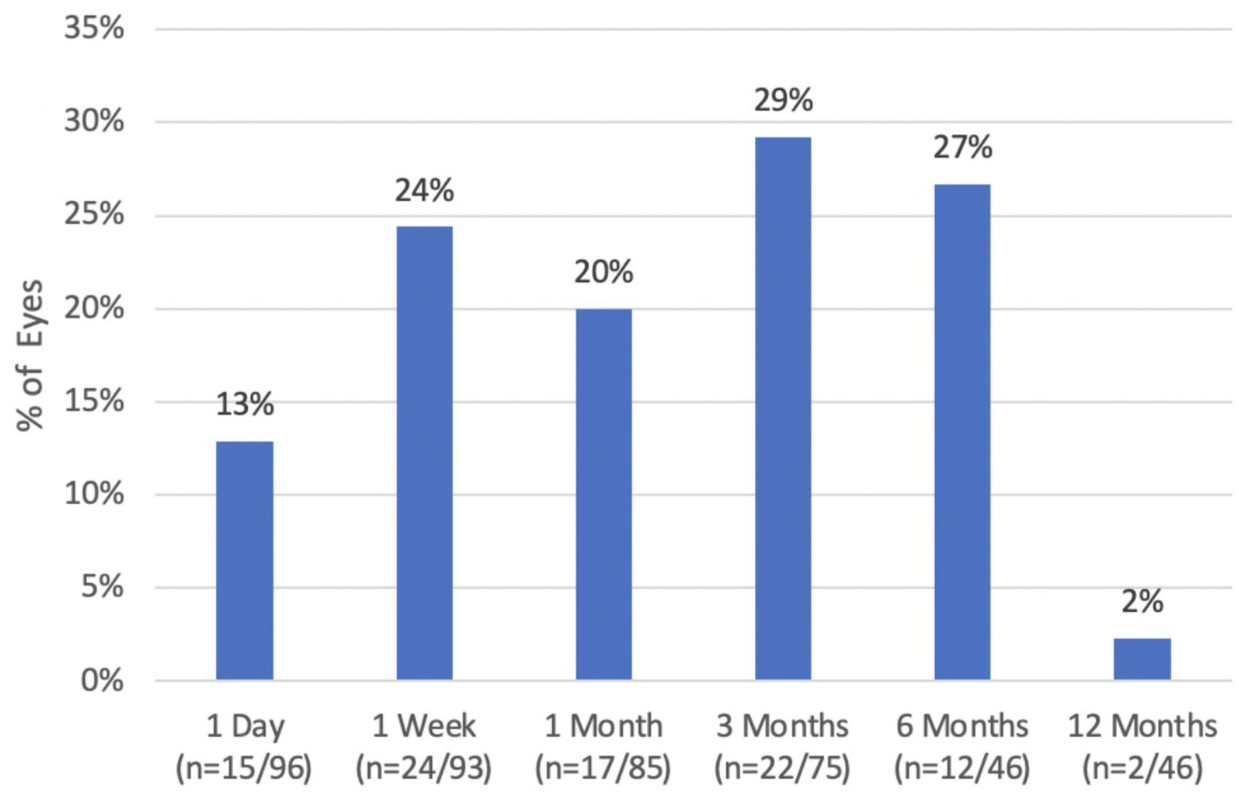

Figure 7 Percentage of eyes with reported dryness at postoperative follow-up $(n=$ number of symptomatic eyes over eyes at follow-up).

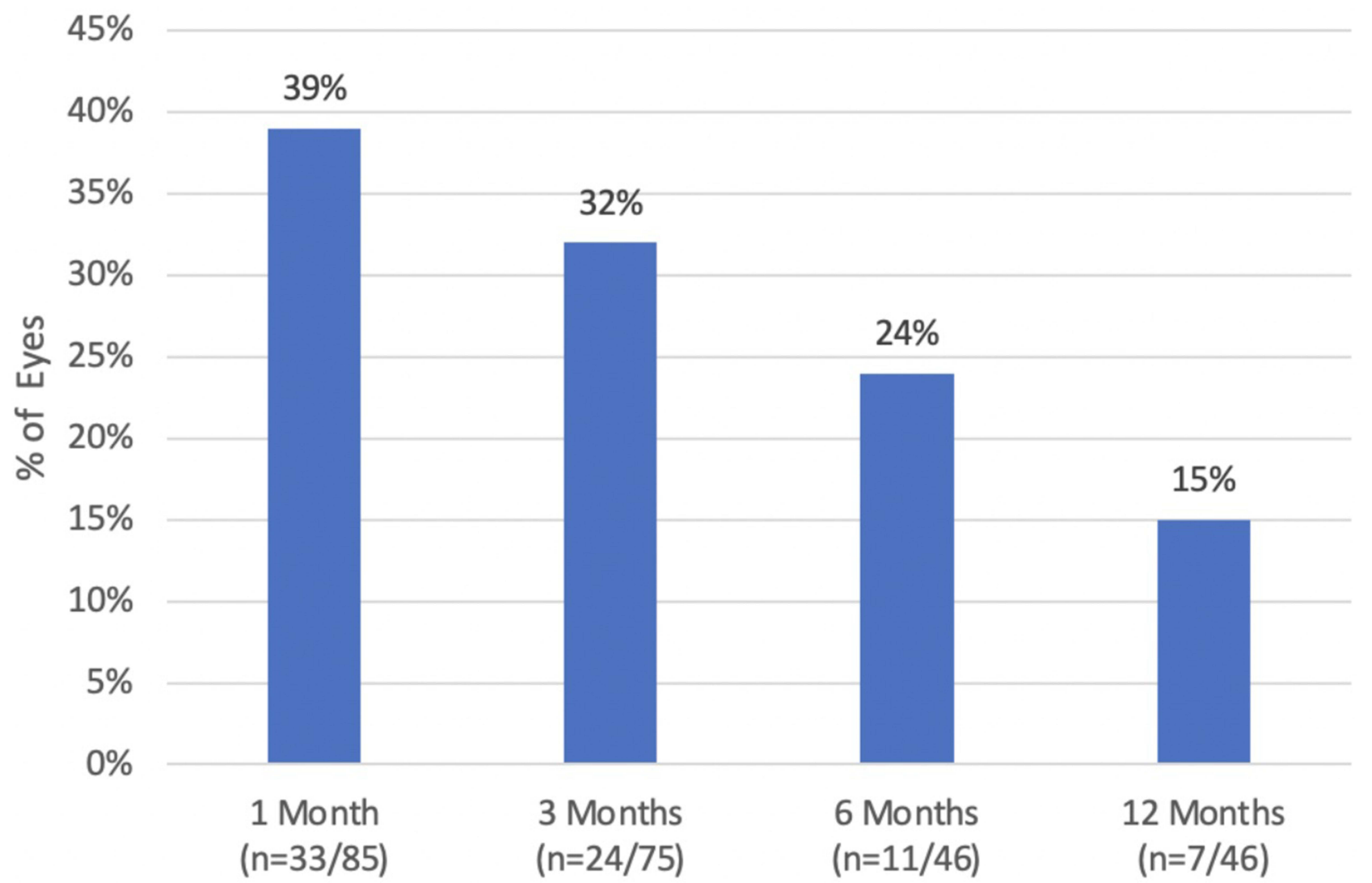

Figure 8 Percentage of patients with reported glare/halos at postoperative follow-up ( $\mathrm{n}=$ number of symptomatic eyes over eyes at follow-up). 
Table 4 Toric ICL Outcomes Compared Between the Present Study and the Literature

\begin{tabular}{|c|c|c|c|c|c|c|c|c|c|c|}
\hline Study & Year & Eyes & Time & $\begin{array}{l}\text { MRSE } \pm \text { SD } \\
\text { (Range) D }\end{array}$ & $\begin{array}{c}\text { Abs MRC* } \pm \text { SD } \\
\text { Range) D }\end{array}$ & $\begin{array}{l}\text { UDVA 20/ } \\
20 \text { or } \\
\text { Better (\%) }\end{array}$ & $\begin{array}{c}\% \\
\text { MRSE/MRC } \\
\pm 0.50 \\
\text { D Intended }\end{array}$ & $\begin{array}{c}\% \\
\text { MRSE/MRC } \\
\pm 1.00 \\
\text { D Intended }\end{array}$ & $\begin{array}{l}\text { Safety } \\
\text { Index }\end{array}$ & $\begin{array}{c}\text { Efficacy } \\
\text { Index }\end{array}$ \\
\hline \multirow[t]{3}{*}{$\begin{array}{l}\text { Present } \\
\text { study }\end{array}$} & \multirow[t]{3}{*}{2021} & 96 & Preop & $\begin{array}{l}-10.31 \pm 3.10 \\
(-4.88 \text { to }-21.75)\end{array}$ & $\begin{array}{l}2.67 \pm 1.02 \\
(1.50 \text { to } 5.75)\end{array}$ & - & - & - & - & - \\
\hline & & 75 & $3 \mathrm{mo}$ & $\begin{array}{l}-0.33 \pm 1.12 \\
(-6.75 \text { to }+2.00)\end{array}$ & $\begin{array}{l}0.68 \pm 0.38 \\
(0.00 \text { to } 1.50)\end{array}$ & 62 & $77 / 44$ & $95 / 89$ & 1.14 & 0.92 \\
\hline & & 46 & $12 \mathrm{mo}$ & $\begin{array}{l}-0.23 \pm 0.47 \\
(-1.25 \text { to } 1.50)\end{array}$ & $\begin{array}{l}0.73 \pm 0.51 \\
(0.25 \text { to } 3.00)\end{array}$ & 74 & $79 / 49$ & $93 / 86$ & 1.10 & 0.98 \\
\hline $\begin{array}{l}\text { FDA } \\
\text { Clinical } \\
\text { Endpoints }^{8}\end{array}$ & 2018 & - & - & - & - & - & $50 / 40$ & $75 / 65$ & - & - \\
\hline \multirow{3}{*}{$\begin{array}{l}\text { FDA } \\
\text { Clinical } \\
\text { Trial }^{8}\end{array}$} & \multirow[t]{3}{*}{2018} & 210 & Preop & $\begin{array}{l}-9.37 \pm 2.67 \\
(-2.38 \text { to }-19.50)\end{array}$ & $\begin{array}{l}1.95 \pm 0.84 \\
(1.00 \text { to } 4.00)\end{array}$ & - & - & - & - & - \\
\hline & & 191 & $3 \mathrm{mo}$ & $\begin{array}{l}0.13 \pm 0.39 \\
(-1.25 \text { to }+1.25)\end{array}$ & $\begin{array}{l}0.52 \pm 0.49 \\
(0.00 \text { to } 3.00)\end{array}$ & - & - & - & - & - \\
\hline & & 194 & $12 \mathrm{mo}$ & $\begin{array}{l}0.03 \pm 0.46 \\
(-2.25 \text { to }+1.00)\end{array}$ & $\begin{array}{l}0.52 \pm 0.48 \\
(0.00 \text { to } 3.00)\end{array}$ & 81.9 & $76.9 / 69.1$ & $97.4 / 92.3$ & - & - \\
\hline \multirow{3}{*}{$\begin{array}{l}\text { Sanders } \\
\text { et al }\end{array}$} & \multirow[t]{3}{*}{2007} & 200 & Preop & $-9.36 \pm 2.66$ & $1.93 \pm 0.84$ & - & - & - & - & - \\
\hline & & 175 & $6 \mathrm{mo}$ & - & - & - & $71.3 / 53.4$ & $97.1 / 86.2$ & - & - \\
\hline & & 186 & $12 \mathrm{mo}$ & $0.05 \pm 0.46$ & $0.51 \pm 0.48$ & 83.1 & $76.9 / 48.4$ & $97.3 / 85.5$ & - & - \\
\hline \multirow[t]{2}{*}{$\begin{array}{l}\text { Hyun } \\
\text { et al }^{14}\end{array}$} & \multirow[t]{2}{*}{2017} & \multirow[t]{2}{*}{24} & Preop & $\begin{array}{l}-10.68 \pm 2.44 \\
(-5.57 \text { to }-15.68)\end{array}$ & $\begin{array}{l}2.50 \pm 1.24 \\
(1.00 \text { to } 5.25)\end{array}$ & - & - & - & - & - \\
\hline & & & Postop & $\begin{array}{l}-0.41 \pm 0.48 \\
(-1.50 \text { to } 0.56)\end{array}$ & $\begin{array}{l}0.63 \pm 0.33 \\
(0.00 \text { to } 1.25)\end{array}$ & 62.5 & - & - & 1.14 & 1.06 \\
\hline \multirow[t]{4}{*}{$\begin{array}{l}\text { Kamiya } \\
\text { et al }\end{array}$} & \multirow[t]{4}{*}{2013} & \multirow[t]{4}{*}{50} & Preop & $\begin{array}{l}-9.47 \pm 2.91 \\
(-3.00 \text { to }-17.25)\end{array}$ & $\begin{array}{l}2.23 \pm 1.09 \\
(0.75 \text { to } 6.50)\end{array}$ & - & - & - & - & - \\
\hline & & & $3 \mathrm{mo}$ & $0.05 \pm 0.22$ & $0.50 \pm 0.43$ & 94 & - & - & 1.21 & 1.02 \\
\hline & & & $12 \mathrm{mo}$ & $-0.11 \pm 0.32$ & $0.57 \pm 0.60$ & 90 & - & - & 1.23 & 1.03 \\
\hline & & & $36 \mathrm{mo}$ & $-0.22 \pm 0.37$ & $0.49 \pm 0.41$ & 86 & $82 / 92$ & $98 / 94$ & 1.16 & 0.94 \\
\hline \multirow[t]{2}{*}{$\begin{array}{l}\text { Sheng } \\
\text { et a }\left.\right|^{30}\end{array}$} & \multirow[t]{2}{*}{2012} & \multirow[t]{2}{*}{54} & Preop & $\begin{array}{l}-12.08 \pm 4.22 \\
(-6.00 \text { to }-24.75)\end{array}$ & $\begin{array}{l}1.88 \pm 1.49 \\
(1.00 \text { to } 5.50)\end{array}$ & - & - & - & - & - \\
\hline & & & $8 \mathrm{mo}$ & $-0.41 \pm 0.61$ & $0.41 \pm 0.61$ & $72.2 \%$ & - & - & - & - \\
\hline
\end{tabular}

Note: *MRC reported as absolute magnitude for comparison across studies.

Abbreviations: UDVA, uncorrected distance visual acuity; MRSE, manifest refraction spherical equivalent; D, diopter; MRC, manifest refractive cylinder.

at twelve months may be due to chronic dry eye rather than post-surgical corneal changes.

In the original FDA clinical trial, glare was worse in $15.1 \%$ of patients and halos were worse in $17.8 \%$ of patients at twelve months postoperatively compared to preoperative reports. ${ }^{8}$ Our patients were not interviewed for preoperative symptoms, nor was glare measured distinct from halos. However, at the twelve month followup, $16 \%$ of eyes experienced glare/halos, which is comparable to the initial FDA study.

Most patients in the present study experienced improved vision with no additional surgeries (87\%). This is a benefit compared to bioptics, which inherently requires two procedures. Comparison of Toric ICL implantation to bioptics has 
Table 5 Comparison of Toric ICL Complications and Astigmatism Outcomes Between Present Study and Literature

\begin{tabular}{|c|c|c|c|c|c|c|c|}
\hline Study & Year & $\begin{array}{l}\text { Remove } \\
\text { (\# Eyes) }\end{array}$ & $\begin{array}{l}\text { Replace } \\
\text { (\# Eyes) }\end{array}$ & $\begin{array}{c}\text { Reposition } \\
\text { (\# Eyes) }\end{array}$ & $\begin{array}{l}\text { Observed } \\
\text { Rotation }\end{array}$ & $\begin{array}{l}\text { TIA } \pm \text { SD } \\
\text { (Range) D }\end{array}$ & $\begin{array}{l}\text { SIA } \pm \text { SD } \\
\text { (Range) D }\end{array}$ \\
\hline Present & 2021 & 0 & 0 & 2 & $\begin{array}{l}\leq 5^{\circ}: 87 \% \\
5-15^{\circ}: 11 \% \\
>15^{\circ}: 2 \%\end{array}$ & $2.16 \pm 0.86$ & $1.75 \pm 0.85$ \\
\hline $\begin{array}{l}\text { FDA Clinical } \\
\text { Trial }^{8}\end{array}$ & 2018 & 3 & I & I & $\begin{array}{l}\leq 5^{\circ}: 94.3 \% \\
\leq 10^{\circ}: 97.9 \%\end{array}$ & - & - \\
\hline Sanders et $\mathrm{al}^{5}$ & 2007 & 3 & I & 1 & $\begin{array}{l}\leq 5^{\circ}: 86.9 \% \\
\leq 10^{\circ}: 92.3 \%\end{array}$ & - & - \\
\hline Hyun et al ${ }^{14}$ & 2017 & - & - & - & $\leq 5^{\circ}: 70.8 \%$ & $\begin{array}{l}2.31 \pm 1.24 \\
(1.00 \text { to } 5.22)\end{array}$ & $\begin{array}{l}2.11 \pm 1.09 \\
(0.75 \text { to } 4.50)\end{array}$ \\
\hline
\end{tabular}

Abbreviations: TIA, target induced astigmatism; SIA, surgically induced astigmatism.

shown quicker improvement of visual outcomes with ICL and equivalent visual outcomes. ${ }^{27,28}$ There is still a role for bioptics in patients with severe myopia $>-19.0 \mathrm{D}$ and astigmatism $>4.0 \mathrm{D}^{3}$ One patient in our study with preoperative myopia of $-18.5 \mathrm{D}$ OD and $-20.0 \mathrm{D}$ OS experienced a residual refractive error of -3.0 and $-7.0 \mathrm{D}$, despite bilateral implantation of $-15.5 \mathrm{D}$ sphere and 2.5 D cylinder Toric ICLs. Residual refractive error is likely due to a limitation of lens power, making this patient an ideal bioptics candidate. Bioptics may play a role to refine refraction after Toric ICL as was seen in our eleven patients who underwent enhancements.

Most eyes were implanted with a $12.6 \mathrm{~mm}$ Toric ICL in the present study, compared with an average implantation size of $13.2 \mathrm{~mm}$ in another study, ${ }^{29}$ suggesting that the $13.7 \mathrm{~mm}$ lens size is infrequently utilized. Sheng et al suggest that undersized Toric ICLs, resulting in low vault, are more susceptible to rotation. ${ }^{30}$ Future development of intermediate lens sizes between 12.6 and $13.2 \mathrm{~mm}$ may be beneficial to improve accuracy of lens sizing and ideally minimize postoperative lens rotation.

There are several limitations to the present study. First, data were utilized from bilateral eyes when available to maximize study sample size. Current statistical recommendations suggest randomized inclusion of OD vs OS due to inter-ocular correlations. ${ }^{31}$ Regarding inclusion criteria, the preoperative cylinder of our data exceeded the FDAapproved guideline of 1.0 to $4.0 \mathrm{D}$ at the spectacle plane. Because some patients' astigmatism exceeded the maximum corrective power of the lens, these patients had an expected amount of undercorrection at postoperative time points, which was taken into account with attempted versus achieved calculations. Also, some patients fell outside the approved age range of 21 to 45 years, potentially limiting external validity. Patient attrition limited postoperative sample sizes, though nearly half of patients were seen at twelve months (47.9\%). Although initial data suggest stability of refraction over time, continuity of visual outcomes through the 12month follow-up would further support this conclusion. Finally, most of the biometric data was only collected in the preoperative visit, precluding analysis over time. Specifically, it would be helpful to correlate anterior chamber angles and aqueous depth with postoperative lens rotation.

\section{Conclusion}

The present study contributes a single site's initial outcomes with Toric ICL after FDA approval. In summary, Toric ICL is a safe and effective option for patients with myopic astigmatism seeking surgical correction. Further investigation of the relationship between vault size and ICL size is needed to determine risk factors for postoperative ICL rotation.

\section{Abbreviations}

LASIK, laser-assisted in situ keratomileusis; PRK, photorefractive keratectomy; Toric ICL, Toric Implantable Collamer Lens; FDA, Food and Drug Administration; UBM, ultrasound biomicroscopy; D, Diopter; IOP, intraocular pressure; UDVA, uncorrected distance visual acuity; CDVA, corrected distance visual acuity; OCT, optical coherence tomography; YAG, Yttrium-Aluminum Garnet; PI, peripheral iridotomy; MRSE, manifest refraction spherical equivalent; MRC, manifest refractive cylinder; TIA, target induced astigmatism; SIA, surgically induced astigmatism; LRI, limbal relaxing incisions. 


\section{Ethics Approval and Informed Consent}

All patients were fully informed and consented to treatment. Eight patients underwent off-label Toric ICL implantation due to age $<21$ years or $>45$ years and were consented and counseled appropriately. All methods and procedures followed the tenets of the Declaration of Helsinki and were approved by the Hoopes Vision Research Review Board. Biomedical Research Alliance of New York (Brany) Institutional Review Board (New York) approved this study.

\section{Consent}

This retrospective study using de-identified data has been approved by the Hoopes Vision Ethics Board and BRANY IRB \#20-12-547-823 (New York, NY, USA). The study conforms with the Helsinki Declaration of 1964, as revised in 2013, concerning human and animal rights. The patients signed informed consent.

\section{Acknowledgments}

Special thanks to Anne Duong, Robert Thomson, and William West for their assistance with data acquisition, analysis, and management.

\section{Author Contributions}

All authors take responsibility for the integrity of the work, and have given final approval to the version to be published. All authors made substantial contributions to conception and design, acquisition of data, or analysis and interpretation of data; took part in drafting the article or revising it critically for important intellectual content; agreed to submit to the current journal; gave final approval of the version to be published; and agreed to be accountable for all aspects of the work.

\section{Funding}

This study was funded by an unrestricted grant from Research to Prevent Blindness (RPB), 360 Lexington Avenue, 22nd Floor New York, NY 10017. No support was received for the publication of this article.

\section{Disclosure}

The authors report no conflicts of interest in this work.

\section{References}

1. Ganesh S, Brar S, Pawar A. Matched population comparison of visual outcomes and patient satisfaction between 3 modalities for the correction of low to moderate myopic astigmatism. Clin Ophthalmol. 2017;11:1253-1263. doi:10.2147/OPTH.S127101
2. Hashemian SJ, Farrokhi H, Foroutan A, et al. Ocular higher-order aberrations changes after implantable collamer lens implantation for high myopic astigmatism. J Curr Ophthalmol. 2018;30(2):136-141. doi:10.1016/j.joco.2017.10.002

3. Moshirfar M, Thomson RJ, West Jnr WB, et al. Visual outcomes after sequential posterior chamber phakic iol with corneal refractive surgery (Bioptics) for the treatment of myopic astigmatism. Clin Ophthalmol. 2020;14:4337-4346. doi:10.2147/OPTH.S285140

4. Jabbour S, Bower KS. Three-year outcomes of implantable collamer lens followed by excimer laser enhancement ("bioptics") in the treatment of high myopic astigmatism. Clin Ophthalmol. 2021;15:635-643. doi:10.2147/OPTH.S283888

5. Sanders DR, Schneider D, Martin R, et al. Toric implantable collamer lens for moderate to high myopic astigmatism. Ophthalmology. 2007;114(1):54-61. doi:10.1016/j.ophtha.2006.08.049

6. Kamiya K, Shimizu K, Kobashi H, Igarashi A, Komatsu M. Threeyear follow-up of posterior chamber toric phakic intraocular lens implantation for moderate to high myopic astigmatism. PLoS One. 2013;8(2). doi:10.1371/journal.pone.0056453

7. Alfonso JF, Madrid-Costa D, Fernandes P, Jorge J, Montés-Micó R. Collagen copolymer toric posterior chamber phakic intraocular lenses to correct high myopic astigmatism. $J$ Cart Refract Surg. 2010;36:1349-1357. doi:10.1016/j.jcrs.2010.02.022

8. Visian ${ }^{\circledR}$ Toric ICL (Implantable Collamer ${ }^{\circledR}$ Lens) - P030016/S001 | FDA. Available from: https://www.fda.gov/medical-devices/recentlyapproved-devices/visianr-toric-icl-implantable-collamerr-lensp030016s001. Accessed May 12, 2021

9. Astigmatism Double Angle Plot Tool | ASCRS. Available from: https://ascrs.org/tools/astigmatism-double-angle-plot-tool/. Accessed May 18, 2021

10. Abulafia A, Koch DD, Holladay JT, Wang L, Hill W. Pursuing perfection in intraocular lens calculations: IV. Rethinking astigmatism analysis for intraocular lens-based surgery: suggested terminology, analysis, and standards for outcome reports. $J$ Cataract Refract Surg. 2018;44(10):1169-1174. doi:10.1016/j.jcrs.2018.07.027

11. Reinstein DZ, Archer TJ, Randleman JB. JRS standard for reporting astigmatism outcomes of refractive surgery. J Refract Surg. 2014;30 (10):654-659. doi:10.3928/1081597X-20140903-01

12. Chen K, Hu Z, Zhou J, et al. Vector Analysis of the Effects of FS-LASIK and Toric ICL for Moderate to High Astigmatism Correction. J Ophthalmol. 2018;2018. doi:10.1155/2018/6952710

13. Gomez-Bastar A, Jaimes M, Graue-Hernández EO, Ramirez-Luquin T, Ramirez-Miranda A, Navas A. Long-term refractive outcomes of posterior chamber phakic (spheric and toric implantable collamer lens) intraocular lens implantation. Int Ophthalmol. 2014;34 (3):583-590. doi:10.1007/s10792-013-9860-1

14. Hyun J, Lim DH, Eo DR, Hwang S, Chung ES, Chung TY. A comparison of visual outcome and rotational stability of two types of toric implantable collamer lenses (TICL): V4 versus V4c. PLoS One. 2017;12(8). doi:10.1371/journal.pone.0183335

15. Kocová H, Vlková E, Michalcová L, Rybárová N, Motyka O. Incidence of cataract following implantation of a posterior-chamber phakic lens ICL (Implantable Collamer Lens) - long-term results. Ces a Slov Oftalmol Cas Ces Oftalmol Spol a Slov Oftalmol Spol. 2017;73(3):87-93.

16. Fernandes P, González-Méijome JM, Madrid-Costa D, Ferrer-Blasco T, Jorge J, Montés-Micó R. Implantable collamer posterior chamber intraocular lenses: a review of potential complications. $J$ Refract Surg. 2011;27(10):765-776. doi:10.3928/1081597X-20110617-01

17. Kojima T, Kitazawa Y, Nakamura T, et al. Prospective Randomized Multicenter Comparison of the Clinical Outcomes of V4c and V5 Implantable Collamer Lenses: a Contralateral Eye Study. J Ophthalmol. 2018;2018. doi:10.1155/2018/7623829

18. Alfonso JF, Lisa C, Palacios A, Fernandes P, González-Méijome JM, Montés-Micó R. Objective vs subjective vault measurement after myopic implantable collamer lens implantation. Am J Ophthalmol. 2009;147(6):978-983.e1. doi:10.1016/j.ajo.2009.01.006 
19. Brar S, Gautam M, Sute SS, Pereira S, Ganesh S. Visual and refractive outcomes with the eyecryl phakic toric iol versus the visian toric implantable collamer lens: results of a 2-year prospective comparative study. J Refract Surg. 2021;37(1):7-19. doi:10.3928/1081597X20201013-04

20. Eissa SA, Sadek SH, El-Deeb MWA. Anterior chamber angle evaluation following phakic posterior chamber collamer lens with centraFLOW and its correlation with ICL vault and intraocular pressure. J Ophthalmol. 2016;2016. doi:10.1155/2016/1383289.

21. Elmohamady MN, Abdelghaffar W. Anterior Chamber Changes After Implantable Collamer Lens Implantation in High Myopia Using Pentacam: a Prospective Study. Ophthalmol Ther. 2017;6 (2):343-349. doi:10.1007/s40123-017-0109-3

22. Davis MJ, Epstein RJ, Dennis RF, Cohen JA. Culture-positive endophthalmitis after implantation of intraocular Collamer lens. $J$ Cataract Refract Surg. 2009;35(10):1826-1828. doi:10.1016/j. jcrs.2009.05.020

23. Yu EYW, Leung A, Rao S, Lam DSC. Effect of laser in situ keratomileusis on tear stability. Ophthalmology. 2000;107(12):2131-2135. doi:10.1016/S0161-6420(00)00388-2

24. Lee JB, Ryu CH, Kim JH, Kim EK, Kim HB. Comparison of tear secretion and tear film instability after photorefractive keratectomy and laser in situ keratomileusis. J Cataract Refract Surg. 2000;26 (9):1326-1331. doi:10.1016/S0886-3350(00)00566-6

25. Sutu C, Fukuoka H, Afshari NA. Mechanisms and management of dry eye in cataract surgery patients. Curr Opin Ophthalmol. 2016;27 (1):24-30. doi:10.1097/ICU.0000000000000227
26. Mencucci R, Vignapiano R, Rubino P, et al. Iatrogenic Dry Eye Disease: dealing with the Conundrum of Post-Cataract Discomfort. A P.I.C.A.S.S.O. Board Narrative Review. Ophthalmol Ther. 2021;10 (2):211. doi:10.1007/s40123-021-00332-7

27. Choi SH, Lee MO, Chung ES, Chung TY. Comparison of the toric implantable collamer lens and bioptics for myopic astigmatism. $J$ Refract Surg. 2011;27(2):91-97. doi:10.3928/1081597X20100414-01

28. Alfonso JF, Lisa C, Fernández-Vega Cueto L, Fernandes P, GonzálezMéijome JM, Montés Micó R. Comparison of visual and refractive results of Toric Implantable Collamer Lens with bioptics for myopic astigmatism. Graefe's Arch Clin Exp Ophthalmol. 2013;251 (3):967-975. doi:10.1007/s00417-012-2155-9

29. Singh R, Vanathi M, Kishore A, Tandon R, Singh D. An anterior segment optical coherence tomography study of the anterior chamber angle after implantable collamer lens-V4c implantation in Asian Indian Eyes. Indian $J$ Ophthalmol. 2020;68(7):1418-1423. doi:10.4103/ijo.IJO_1540_19

30. Sheng XL, Rong WN, Jia Q, et al. Outcomes and possible risk factors associated with axis alignment and rotational stability after implantation of the Toric implantable collamer lens for high myopic astigmatism. Int $J$ Ophthalmol. 2012;5(4):459-465. doi:10.3980/j. issn.2222-3959.2012.04.10

31. Armstrong RA. Statistical guidelines for the analysis of data obtained from one or both eyes. Ophthalmic Physiol Opt. 2013;33(1):7-14. doi:10.1111/opo.12009
Clinical Ophthalmology

\section{Publish your work in this journal}

Clinical Ophthalmology is an international, peer-reviewed journal covering all subspecialties within ophthalmology. Key topics include: Optometry; Visual science; Pharmacology and drug therapy in eye diseases; Basic Sciences; Primary and Secondary eye care; Patient Safety and Quality of Care Improvements. This journal is indexed on PubMed

\section{Dovepress}

Central and CAS, and is the official journal of The Society of Clinical Ophthalmology (SCO). The manuscript management system is completely online and includes a very quick and fair peer-review system, which is all easy to use. Visit http://www.dovepress.com/ testimonials.php to read real quotes from published authors. 